\title{
A TRAJETÓRIA DOS CHIRU NA CONSTRUÇÃO DA TRADIÇÃO DE CONHECIMENTO KAIOWA*
}

Fabio Mura

\begin{abstract}
Vieram três crianças; pareciam crianças, mas não eram, apenas se transformaram em crianças, para me contar e conversar comigo, pedindo minha opinião sobre suas propostas. Primeiro me falaram, me ordenaram continuar orando para os chiru. Consideraram-me como chiru, me chamaram de chiru (Xamã Atanásio Teixeira, T.I. Limão Verde, 30/05/2004).
\end{abstract}

\section{Introdução'}

É possível afirmar que, ao menos na atualidade, os Kaiowa ${ }^{2}$ exercem pouca atividade técnica para a conservação da maioria dos seus objetos. Os instrumentos e adornos rituais, de sua parte, recebem inegavelmente mais cuidados, mas é também de se observar que entre eles próprios há distinções, no que tange ao rigor empregado no processo construtivo, à sua forma e substância, ao seu uso e lógica de distribuição, bem como a uma hierarquia de poder que lhes é atribuída. Destes objetos, Melià e os cônjuges Grünberg fazem uma classificação, em duas distintas categorias: os que estão relacionados com o aspecto divino - que adornam as pessoas, fazendo-as assim assemelhar-se às divindades - e aqueles que se relacionam com o "dizer" - que permitem uma comunicação, trazendo palavras dos deuses ou levando-as a eles (Melià et alii 1976:246).

Em relação aos adornos (de cabeça, tórax, cintura e braços), pode-se dizer que, ao sofrerem desgastes, são frequentemente substituídos, havendo pouco rigor na definição formal e na utilização dos materiais empregados, hoje podendo ser integrados inclusive aqueles de origem industrial. Já os objetos rituais relacionados com o "dizer" são mais padronizados, ganhando destaque, na literatura, o mbaraka (chocalho), invariavelmente construído com cabaça (hy'akua). Deve-se registrar, porém, que no que diz respeito aos adornos dos próprios mbaraka, assim como aos materiais (sementes, madeiras e pedras) 
que produzem o som por eles emitidos, existe hoje uma diversidade de padrões construtivos, dependendo da destinação que lhes será dada. É comum nas casas de reza da reserva ${ }^{3}$ de Dourados (Mato Grosso do Sul) encontrar mbaraka que são destinados ao comércio (como "artesanato"), ao lado de outros, que são realmente utilizados nos rituais. Onde reside a diferença, perguntaríamos. Montardo (2009) relata o processo construtivo de um destes instrumentos, por parte de uma importante ñandesy (xamã) kaiowa, dona Ordúlia, apontando os cuidados construtivos - em relação à escolha dos materiais internos, às atividades técnicas e mágicas, bem como ao seu uso e cuidados destinados a fazer com que o mbaraka "vá ganhando vida e comece a falar" (Montardo 2009:164). Neste sentido, a forma pareceria menos relevante do que suas propriedades (percebidas como a alma e a voz desse objeto). Por conseguinte, compreende-se que os mbaraka destinados ao comércio seriam meros objetos, desprovidos de sua função principal: o poder de comunicar.

A propriedade do mbaraka falar é um aspecto recorrente na literatura e nas fontes coloniais, conforme destacado por Wilde (2008) e Montardo (2009). Há que se considerar, porém, que a tônica é posta sobre o falar "através de", sendo os objetos considerados quase que exclusivamente como meios de uma comunicação, de modo que os estudos se concentram nas características dessa comunicação em si - que seria estabelecida entre os Homens e as Divindades, produzindo-se assim uma "etnografia da palavra" (cf. Melià et alii 1976; Chamorro 1995, 1998; Montardo 2009).

Esta ênfase dada ao objeto ritual como "meio" pode ser, talvez, um dos motivos que levaram os autores que se dedicaram aos Kaiowa a não aprofundar pesquisas sobre as características de outros instrumentos, sumamente valorizados por estes indígenas. Trata-se aqui dos chiru, varas e cruzes derivadas de um tipo específico de madeira (myroxylon peruiferum) ${ }^{4}$ que são transmitidos e conservados por gerações. Tal importância dada pelos índios aos chiru deve-se ao fato de estes não serem considerados meros objetos, nem meros veículos, mas também sujeitos de ação.

Foi esta evidente falta de congruência entre as visões de pesquisadores e de indígenas sobre estes objetos/sujeitos que me levou a buscar aprofundar o seu papel nas relações sociais, cosmológicas e na reprodução de uma tradição de conhecimento específica, baseada no xamanismo, na qual o vínculo entre os Kaiowa e os chiru demonstra-se sumamente relevante. ${ }^{5}$ Chamaram-me muito a atenção as palavras de Orlando Turíbio, um líder político kaiowa, que, ao ser expulso (por integrantes de famílias rivais) de uma Terra Indígena, queixou-se do fato de não ter sido dado a seu pai tempo de levar consigo os chiru, afirmando: "O senhor sabe, os chiru não podem ser abandonados; é muito perigoso". Com efeito, os chiru acompanham os Kaiowa ao longo da história, 
representando elementos poderosos na intermediação entre este povo e as várias dimensões do universo. Existe, portanto, uma íntima conexão entre essa relação (dos Kaiowa com os chiru) e o próprio equilíbrio do cosmo.

Há ainda uma outra especificidade dessa relação que merece ser destacada. Ocorre que os chiru não são distribuídos casualmente e não dizem respeito a uma coletividade kaiowa genérica. Eles estão ligados a famílias específicas e, em seu interior, a indivíduos igualmente específicos, cujos corolários veremos no decorrer do trabalho. Assim sendo, existe um paralelismo entre a trajetória histórica das famílias (e dos xamãs que delas fazem parte) e a trajetória dos chiru a elas relacionada. Por sua vez, ambas trajetórias estão condicionadas pelas características das situações históricas vivenciadas pelos índios. Sem dúvida, os efeitos da dominação colonial e neocolonial (principalmente a perda do controle territorial) representaram para os Kaiowa fatores muito relevantes, com os quais foram obrigados a defrontar-se e, em resposta aos quais, devem determinar estratégias e modalidades voltadas a melhor reproduzir sua própria organização social e tradição de conhecimento. Nas últimas décadas, o papel dos chiru exerce grande importância justamente na definição destas estratégias e modalidades, devendo os índios buscar formas inéditas de lidar, distribuir e cuidar destes importantes objetos/sujeitos, conforme se verá.

O objetivo deste trabalho, portanto, é abordar a trajetória e o papel dos chiru entre os Kaiowa, buscando levar em conta os aspectos aqui destacados e sua inter-relação.

Num primeiro item, serão apresentadas as diferentes situações históricas pelas quais passaram os Kaiowa, procurando-se colocar em destaque os efeitos da dominação colonial e neocolonial, bem como as respostas organizativas indígenas. No item a seguir, será considerada a trajetória das "cruzes" e "varas" ao longo dos séculos, discutindo-se sua interpretação a partir da relação entre forma e substância, levando-se em conta a perspectiva indígena e a dos agentes coloniais. Em um terceiro momento, serão brevemente apresentadas as especificidades da cosmologia kaiowa, bem como das práticas xamanísticas, contextualizando, deste modo, o papel dos chiru numa dimensão não apenas histórica, mas cosmo-histórica. O quarto item procura descrever as propriedades dos diferentes tipos de chiru, bem como suas origens, seus poderes e seus efeitos sobre a ordem cósmica. No quinto item, apresentam-se casos específicos, referidos às trajetórias dos chiru nas reservas de Dourados e Sassoró, em Mato Grosso do Sul, mostrando os efeitos da dominação neocolonial por parte de agentes indigenistas e missionários, assim como as estratégias elaboradas pelos índios para controlar as situações negativas, procurando reequilibrar as forças do cosmo. Finalmente, no 
sexto item, busca-se discutir, numa perspectiva introduzida pelos últimos estudos de Fredrik Barth, as características da tradição de conhecimento desenvolvida pelos Kaiowa, bem como o papel que jogam justamente os chiru nos mecanismos de reprodução desta tradição — especialmente à luz das mudanças ocorridas nos territórios desses indígenas, por efeitos das relações assimétricas estabelecidas com os brancos.

\section{Situações históricas e dominação colonial}

Os Kaiowa são descendentes de um povo guarani originário da região denominada pelos colonizadores europeus, Província do Itatim - localizada entre a serra da Bodoquena e o Pantanal sulmatogrossense. As reduções jesuíticas ali formadas tiveram vida relativamente breve, sendo alvo dos ataques de bandeirantes paulistas e dos Mbaya-Guaicuru, resultando na destruição das missões, na morte, escravização e afugentamento dos indígenas sobreviventes (não só aqueles das missões), já nas primeiras décadas do século XVII. A fuga destes índios deu-se em direção sudeste, para além dos rios Apa e Aquidaban, vindo a assentarem-se em uma ampla região no interior dos espaços geográficos hoje conhecidos como o Paraguai oriental e o cone sul do estado de Mato Grosso do Sul, ${ }^{6}$ somando uma superfície superior aos $50.000 \mathrm{~km}^{2}$ (Melià et alii 1976; Susnik 1979-80; Gadelha 1980; Thomaz de Almeida 1991).

Para o período após a destruição das reduções jesuíticas do Itatim, dispomos de poucas e fragmentárias informações. Ao findar do século XVII, o interesse da colônia portuguesa pela mão de obra indígena passou a declinar frente à descoberta, no Mato Grosso, de pedras e metais preciosos, novo alvo dos empreendimentos da coroa (v. Mura e Thomaz de Almeida 2002:11). Ao serem localizadas, ao norte da província, as minas tornaram-se imediatamente objeto da atenção, permanecendo amplos espaços territoriais praticamente inexplorados por longos períodos de tempo e, entre estes, justamente aqueles ocupados pelos Guarani em questão.

Foi preciso aguardar até meados do século XIX para que se obtivessem significativas informações sobre a presença guarani, desta vez procedentes de duas expedições encomendadas pelo Barão de Antonina - com o objetivo de encontrar uma rota apropriada que comunicasse Mato Grosso com o Paraná (Elliot 1848; Lopes 1850). Mas seriam os enfrentamentos bélicos entre Brasil e Paraguai, no mais amplo contexto da guerra da "Tríplice Aliança"7 (1864-70), que marcariam fortemente a sorte dos Kaiowa. De fato, a redefinição das linhas de fronteira entre os dois países levou à ocupação progressiva dos espaços territoriais ocupados pelos índios (Corrêa Filho 
1969; Thomaz de Almeida 1991; Mura e Thomaz de Almeida 2002; Brand 1997 e 2001). Num primeiro momento, a concessão do Estado brasileiro à Cia. Matte Larangeira para exploração dos ervais na região conduziu ao estabelecimento de um contato entre brancos e índios, baseado numa relação de trabalho em que os Guarani (Kaiowa e Ñandéva) ofereciam mão de obra para a extração da erva mate. Contudo, obtida simplesmente uma concessão e com suas atividades limitando-se à extração, a Cia. não pretendeu ocupar capilarmente as terras utilizadas pelos índios, vindo involuntariamente a realizar uma proteção destas últimas, visto que impedia a penetração de outras frentes neocoloniais. Assim sendo, até a primeira década do século $\mathrm{XX}$, os Kaiowa não sofreram significativas mudanças em sua organização territorial, limitando-se as famílias extensas a incorporar os trabalhos prestados periodicamente (a changa) em suas estratégias técnicoeconômicas de apropriação de bens materiais por eles não produzidos.

A situação mudou nas décadas seguintes, quando a Cia. perdeu a concessão exclusiva, e novos colonos passaram progressivamente a ocupar o extremo sul do então estado de Mato Grosso. Nesse mesmo período, passou a atuar na região o Serviço de Proteção aos Índios (SPI) que, entre 1915 e 1928, instituiu oito reservas, sob supervisão de "chefes de posto", destinadas ao aldeamento dos Guarani. O aldeamento tinha o duplo objetivo de subtraí-los à exploração por parte de colonos e ervateiros e liberar espaços para a colonização (Lima 1995). Contudo, há que se levar em conta que, por muitas décadas, esta ação de Estado não passou de uma tentativa incompleta de aldeamento, a maioria das famílias extensas permanecendo nas amplas matas da região, assentadas nas cabeceiras de rios e córregos. Mesmo aquelas que permaneciam nas reservas mantinham um alto grau de mobilidade territorial, estabelecendo alianças por parentesco com as que viviam fora das reservas. Tal fato as levava a mudar periodicamente de lugar, criando-se uma circulação entre várias localidades definidas como tekoha ("lugar onde realizamos nosso modo de ser e viver") (Melià et alii 1976), no interior daquilo que hoje é denominado pelos índios tekoha guasu (guasu = grande, amplo) - ver Lehner (2002) e Mura (2004 e 2006).

Até meados dos anos 1960 havia, assim, redes de famílias indígenas que ocupavam e usavam significativa parte de seus territórios, embora estes não fossem mais exclusivos, sendo muitos espaços compartilhados com ervateiros, colonos e fazendeiros. Até aquele momento, a ação colonizadora não produziu grandes efeitos nas reservas.

Uma mudança radical, contudo, ocorreu entre os anos 1960 e 70, quando a maior parte das extensas matas da região foi derrubada para o incremento das fazendas (tanto das já existentes quanto de novas), e os índios compulso- 
riamente retirados de seus lugares tradicionais. Naquele período, as reservas tiveram sua população duplicada ou mesmo triplicada. Famílias pertencentes a diferentes grupos políticos e mesmo inimigas foram obrigadas a conviver nos exíguos espaços reservados. Nessa situação, a eficácia da intervenção dos agentes coloniais aumentou, permitindo a construção de estruturas de poder que tiveram significativas consequências sobre a organização interna das reservas, favorecendo a consolidação do papel de "capitão" indígena, instituído pelo SPI para mediar as relações com essa população. Conjuntamente, para transformar as características morfológicas e de organização social indígenas, agiam também as missões religiosas, especialmente a Missão Evangélica Caiuá (MEC) que se implantara na região em pauta em 1928 (v. Thomaz de Almeida 1991). Criava-se, assim, uma tríade, composta por chefe de posto, pastor e "capitão", que impunha regras políticas e lógicas de desenvolvimento alheias à tradição indígena. Isto ocorria muitas vezes porque, apoiadas nesse suporte externo, algumas famílias indígenas podiam exercer com maior eficácia poder sobre as rivais, não significando que se teriam convertido a ou assumido outra ótica comportamental. O fator cultural básico permanecia o mesmo, sendo que a acusação de práticas de feitiçaria (dirigida aos xamãs relacionados a famílias não aliadas), por exemplo, constituiu uma significativa arma nas mãos dos missionários, que conseguiram, por certo período, isolar os xamãs de muitas famílias, que temiam ser atingidas por doenças - estas sendo consideradas obra de algum feiticeiro (Mura 2006).

Embora com eficácia variável, dependendo das características de cada reserva e da capacidade dos Kaiowa de contornar essas práticas colonizadoras, em alguns locais esse procedimento assumiu conotações dramáticas, cometendo-se atos de violência física e psicológica para com as famílias que rejeitavam o novo ordenamento político-religioso. Através do instrumento representado pela autoridade do "capitão", missionários e chefes de posto conseguiam instaurar um clima de terror no interior dessas reservas (cf. Thomaz de Almeida 2001).

O sistemático desmatamento da região, com a consequente expulsão das famílias dos lugares antigamente ocupados, e o estado dramático das reservas constituíram uma situação insustentável para a vida indígena, a ponto de, já no final dos anos 1970, iniciar-se um processo de reivindicação fundiária, que foi se avolumando e que, até o momento, impulsionou a identificação de outras 24 áreas indígenas kaiowa e ñandéva (Mura 2006). As reivindicações indígenas decorrem das demandas de conjuntos de famílias extensas aliadas, que constituem comunidades políticas com origem num determinado lugar e que são autônomas ao determinar o processo de luta que lhes diz respeito, sem uma organização centralizada do movimento. Nesse 
sentido, mantém-se a tradicional autonomia das famílias indígenas em relação às suas decisões políticas. Porém, o movimento inaugurado no final dos anos 1970 assume características étnicas expressas na formação de um organismo intercomunitário, a aty guasu (assembleia geral) dos Guarani de Mato Grosso do Sul, que projeta a nível étnico as características das aty guasu tradicionalmente realizadas no interior de cada comunidade, podendo os participantes trocar informações e estabelecer estratégias comuns de apoio às reivindicações específicas, deixando-se as decisões nas mãos das famílias. Esses encontros periódicos (a cada três ou quatro meses), envolvendo participantes de lugares distantes, requeriam grandes esforços para reunir as pessoas num determinado local, sendo necessário suporte externo, para transporte e alimentação, por exemplo. Foi a partir do apoio do Projeto Kaiowa-Ñandeva (PKÑ) - criado em 1976 e conduzido por antropólogos — que os índios puderam realizar as primeiras aty guasu intercomunitárias. Nos anos 1980, juntou-se a esse apoio aquele do Conselho Indigenista Missionário (CIMI), e hoje essas reuniões contam igualmente com recursos da FUNAI.

Conjuntamente a essas aty guasu, mas com certa intermitência, realizavam-se também os jeroky guasu (grande ritual religioso), que reuniam xamãs (ñanderu), seus assistentes (yvyra'ija), adultos e crianças. Nessas ocasiões, discutia-se a situação da vida ética dos Kaiowa e dos Nandéva, interpretando-se a situação do cosmo. Em alguns desses encontros, os xamãs mais prestigiosos anunciavam as regras do tekorã, ou seja, o modo de ser que deveria vigorar a partir daquele momento, e que lhes fora comunicado pelas divindades durante as viagens xamanísticas (Mura 2006).

Sumarizando, esta descrição dos processos pelos quais passaram os Kaiowa coloca em evidência mudanças marcantes para estes índios ao longo de quase quatro séculos de história. De uma situação histórica (Oliveira 1988) em que eram controladores dos espaços territoriais onde desenvolviam suas vidas, estes indígenas passaram a lidar com as práticas de avassalamento dos encomenderos espanhóis e dos jesuítas, e aquelas escravizadoras e exterminadoras dos bandeirantes paulistas. Isto implicou a necessidade de adequação, em um primeiro momento, às características centralizadoras e de urbanização das reduções jesuíticas por parte de algumas famílias. Em um segundo momento, os índios (das missões ou não) sofreram enormes baixas, com forte redução populacional causada pelos ataques dos bandeirantes, com consequente fuga dos sobreviventes que, todavia, passaram a se organizar nos novos espaços geográficos sem sofrer significativas pressões dos colonizadores brancos durante aproximadamente dois séculos. Por sua vez, o período que se seguiu à guerra da "Tríplice Aliança" representou novamente e de modo definitivo a perda do controle de seus espaços territoriais, passando as frentes 
neocoloniais progressivamente a ocupar as terras guarani, obrigando estes indígenas, como dito, a residirem em minúsculas reservas. Do ponto de vista especificamente da organização doméstica e das atividades ritualísticas, os episódios imediatamente antecedentes à explosão do movimento indígena de demanda fundiária tiveram um forte impacto, como será visto mais adiante.

\section{A trajetória dos chiru}

Os chiru parecem ter perpassado todas as situações históricas descritas no item anterior. Cabe aqui perguntar, porém, se estes importantes "objetos" mantiveram-se constantes na forma, substância, significados e funções a eles atribuídos durante o decorrer dos séculos.

Segundo Wilde (2003), que busca estabelecer uma relação entre símbolos nativos de poder e aqueles introduzidos pelos jesuítas nas reduções, existiria a possibilidade de que os Guarani pré-colombianos se servissem de varas para indicação de formas diferenciadas de status no interior do grupo. Eis sua argumentação:

É pertinente nos perguntarmos se existiu algum símbolo parecido com o bastão de comando em tempos pré-hispânicos que facilitasse sua substituição pelos atributos do cabildo. Segundo o jesuíta Mastrilli Durán, os xamãs guarani usaram varas como signo de autoridade. Esta foi uma das razões pelas quais os missionários, apelando habilmente para o poder que receberam do governador, lograram incorporar uma tradição espanhola de autoridade (Mörner 1994). Guardando as devidas distâncias, deve-se ressaltar que os Mbya-guaraní atuais utilizam dois tipos de bastão-poder, o popygua e o yvyra'i. Ambos ocupam um lugar central em seus mitos e rituais. Baseando-se nas compilações de Cadogan, Hélène Clastres associa o bastão-insígnia aos ossos dos antepassados e seu rito de conservação. Um dos mitos menciona yvyra'ikanga, que é o nome religioso do esqueleto masculino e significa, literalmente, os ossos (= kanga) do bastão-insígnia (= yvyra'i). Segundo esta autora (1989:101), os yvyra'i ou bastões-insígnias eram utilizados pelos homens para dançar nas cerimônias, sendo ligados ao poder masculino. Mas estes símbolos mbya-guarani não se parecem em forma, tamanho nem usos, com aqueles dos cabildos. Em contraste, no caso chiquitano, os bastões são exatamente do tipo hispânico (Wilde 2003:219).

Como fica evidente, o autor concentra-se na tentativa de relacionar o símbolo utilizado com a forma física que estes assumiriam. Neste sentido, as lógicas de autoridade encontrariam na analogia entre as formas dos objetos 
utilizados para representá-las e exaltá-las a possibilidade de se estabelecer uma relação simbólica entre os índios e os missionários. Há que se salientar, contudo que, se compararmos as parcas e heterogêneas informações sobre o argumento referido ao período pré-reducional com aquelas que dizem respeito aos grupos guarani contemporâneos, apresentam-se variáveis que nos induzem a ser prudentes no estabelecimento dessas analogias. O próprio Wilde, citando o caso dos Guarani-Mbya, descreve as diferenças entre as varas utilizadas por estes indígenas e aquelas introduzidas pelos jesuítas. A relação estabelecida a partir de narrativas cosmológicas mbya entre ossos, culto dos mortos, masculinidade e ritual não pode ser estendida a outros grupos guarani contemporâneos, sendo igualmente temerário em termos metodológicos utilizar-se estas informações para tentar esboçar uma interpretação minimamente conclusiva do entendimento que os diversos grupos guarani pré, pós e propriamente reducional tinham dos símbolos em pauta. Os Guarani-Ñandéva, por exemplo - que, segundo a literatura, foram os índios que historicamente tiveram uma relação mais duradoura com a experiência reducional - não utilizam varas nem cruzes, mas penas de tucano, arara ou outros tipos de aves, seguradas pelos xamãs durante os rituais. ${ }^{8}$

Aqueles que de fato parecem utilizar objetos similares aos descritos para o período reducional são os Guarani-Kaiowa. Nesse caso, os chiru assumem a forma de cruzes e varas que podem variar de poucos centímetros a aproximadamente 1,2 metros de comprimento. Ocorre, contudo, que a conotação simbólica atribuída pelos Kaiowa contemporâneos a esses objetos não corresponde minimamente àquela introduzida pelos jesuítas no interior das reduções. Por um lado, os índios não associam a cruz ao sacrifício de Jesus. Na realidade, este símbolo representa o suporte principal da Terra, indicando também os pontos cardeais e outros suportes subsidiários, localizados em torno da linha do horizonte. Já em relação às varas, estas não podem ser consideradas símbolos de mando, uma vez que os Kaiowa as destinam a um uso terapêutico e propiciatório; suas propriedades derivam de sua substância e não de sua forma.

A relação entre substância e forma é um fator relevante para se compreender o processo de integração de objetos simbólicos à vida ritual dos Kaiowa. Com efeito, até mesmo para o período reducional podemos lançar dúvidas sobre uma convergência interpretativa desses objetos, de modo a se constituir um conjunto de significados em comum entre os índios e os jesuítas. A complexa e rica visão cosmológica que os indígenas construíram em torno dos chiru, assim como o uso xamanístico que é feito destes objetos, coloca em evidência a enorme distância da ideologia destes índios em relação ao cristianismo e à organização política ocidental, como ficará evidente. Os símbolos deveriam, 
portanto, ser interpretados como multivocais e polivalentes, conforme as definições de Turner (1974). Nestes termos, os objetos podem ter sido elevados a símbolos a partir de paradigmas ideológicos diferentes, mesmo em um contexto sociopolítico unificado a partir de relações de dominação colonial — como era o caso das reduções jesuíticas. Fica evidente que, no caso dos missionários, o processo de simbolização de cruzes e varas respondia mais a um critério digital, cognição em que a imagem evoca os conceitos codificados, independentemente da substância com a qual esses objetos foram construídos; isto é, os símbolos independem das propriedades intrínsecas do suporte que os veiculam. No caso dos chiru, temos uma situação contrária, na qual a forma se subordina à substância. Para sermos mais corretos, quando nos referimos a estes símbolos considerando-os como "objetos" (mba'e), seria mais apropriado falar em cruz "de" chiru, vara "de" chiru etc. Os Kaiowa fazem questão de dizer, por exemplo, que uma cruz de yvyra paje (Myrocarpus frondosus) não é igual àquela de chiru, sendo a primeira menos poderosa em relação à segunda.

Os índios, portanto, combinam forma e substância, privilegiando a segunda no processo simbólico, o que torna os objetos manipulados ritualmente "símbolos concretos", conforme os define Barth. ${ }^{9}$ Assim, as associações de imagens e matéria deixam prevalecer uma relação mais analógica do que digital. As relações entre substância e forma são também particulares a uma determinada visão de mundo e de um agir xamanístico, aspectos estes que se mostram fundamentais para a compreensão da integração dos chiru na vida cotidiana dos Kaiowa, assim como de sua trajetória histórica. Portanto, antes de descrever as características específicas destes importantes "objetos", dedicarei atenção à arquitetura e à dinâmica do cosmo, destacando as práticas mágicas pertinentes ao tema aqui desenvolvido.

\section{Cosmologia e xamanismo ${ }^{10}$}

A concepção que os Kaiowa têm do cosmo é de que este é extremamente dinâmico, determinando-se relações de natureza política entre os seres que o povoam. Os resultados dessas relações produzem mudanças constantes no cosmo, com transformações na aparência, dimensões e esferas que o compõem. O entendimento de que as relações são preeminentemente políticas deriva do fato de que, para estes índios, não existe no cosmo uma contraposição entre natureza e humanidade, e tampouco entre estas e um eventual mundo sobrenatural. Todos os elementos do universo encontramse na condição de agir ou de serem agidos por outros, sendo as diferenças determinadas através de níveis de eficácia e de hierarquia relacional, e não 
através de dicotomias ontológicas. Desta forma, recuperando a definição de política oferecida por Swartz, Turner \& Tuden na introdução a "Political anthropology" (1966:7), podemos afirmar que as ações dos sujeitos no universo interpretado pelos Kaiowa são públicas, destinadas a alcançar um objetivo e implicam um diferencial de poder. O cosmo torna-se, desse modo, uma grande arena, onde se manifestam disputas, elaboram-se estratégias, buscam-se alianças, exerce-se dominação, procuram-se equilíbrios etc.

Segundo os Kaiowa, para chegar aos dias atuais, o universo teria passado por várias fases, cada uma com suas peculiaridades morfológicas e organizativas. A primeira, cosmogônica e teogônica, foi caracterizada pela geração da divindade principal, Nane Ramõi ("Nosso avô"), e de seus adornos corporais e rituais, a partir de uma substância primordial, denominada jesuka. Na sequência, ainda durante esta fase, servindo-se da jesuka, este personagem criou a arquitetura principal do cosmo - composto de patamares superpostos vertical e horizontalmente (denominados yváy) — assim como as divindades destinadas a povoar tais espaços primordiais e, finalmente, sua própria esposa, Ñande Jari ("Nossa avó"), fazendo-a surgir de seu cocar.

Esta primeira fase do cosmo foi caracterizada por uma organização harmônica e simétrica, envolvendo os personagens que o povoavam. A segunda fase, geogônica e etnogônica, foi inaugurada pelo filho de Ñane Ramõi, Nande Ru ("Nosso pai"), que criou a Terra, do tamanho de um disco de cerca de $10 \mathrm{~cm}$ de diâmetro, bem como os suportes onde este se apoia e as humanidades que nela iriam habitar. Seria Ñande Rykey Pa'i Kuara ("Nosso irmão mais velho, o sol"), principal herói civilizador e filho de Ñande $\mathrm{Ru}$, que iria posteriormente ampliar a superfície desse disco, interagindo diretamente com os seres aí localizados. Esta segunda fase, extremamente dinâmica, foi dominada pelas rivalidades e conflitos desencadeados pelos diferentes povos que habitaram a Terra. Àquela época, todos os sujeitos eram imortais, possuindo poderes xamanísticos e conseguindo comunicarse através de uma linguagem comum. A litigiosidade e os comportamentos mantidos pela maioria dos povos levaram as divindades principais a se exasperarem, a ponto de destruírem a superfície da Terra. Assim, teve início a transformação mais significativa que afetou o universo, concluindo-se o período definido pelos índios como Áry Ypy ("espaço-tempo das origens"). A ira das divindades desencadeou um processo que levou à decadência das humanidades sobreviventes e à destruição da superfície da Terra, sendo a maioria destas destinadas a manifestar-se através de corpos que nós, ocidentais, consideraríamos como espécies animais. Desta forma, dependendo dos atributos de cada uma destas, os povos originários foram destinados a rastejar, fugir, agredir, alimentar-se de carniça etc. 
Não todas as humanidades tiveram este destino, nem a decadência foi de igual intensidade e qualidade para todos os povos. Também em cada povo não foram todos os que perderam totalmente as qualidades originárias. O Áry Ypyrã - isto é, o espaço-tempo atual — é caracterizado, portanto, por iniquidades e diferenças hierárquicas instituídas durante o Áry Ypy. Algumas humanidades foram destinadas a possuir certos objetos, matérias e técnicas, enquanto outras foram preclusas destes benefícios. Os próprios Kaiowa, sendo parentes diretos das divindades, foram incumbidos de cuidar da Terra e dela fazer bom uso, respeitando-se o teko porã ("bom/correto modo de ser"). Outro aspecto importante foi a modificação da própria arquitetura do cosmo: as trilhas que comunicavam os seres da Terra com aqueles dos patamares do céu foram fechadas para a maioria dos indivíduos, somente aos xamãs sendo permitido por elas transitar. Sendo assim, os níveis mais elevados do universo somente podem ser atingidos por rezadores com público reconhecimento de sua sabedoria, algo que denota terem alcançado suficiente pureza e perfeição.

O Áry Ypyrã (espaço-tempo atual) caracteriza-se igualmente pela presença de espíritos "donos" e "guardiães" (os járy) de cada conjunto de seres presentes tanto nos patamares do céu (aqueles benignos) quanto da Terra (malignos ou potencialmente malignos). Os Kaiowa, contudo, embora obrigados a viver na Terra, têm suas almas espirituais procedentes de distintos patamares do céu, sendo seus "donos" justamente as principais divindades do panteão indígena - por eles tidas como Nande Rykey ("Nossos irmãos mais velhos"). A busca constante por se alcançar a perfeição e a purificação dos males da Terra é motivada pelo desejo de juntar-se a seus parentes celestiais, a situação ideal sendo a de transcender em vida, voltando a ser imortal, como seus antepassados, durante o Áry Ypy ("espaço-tempo das origens"). Para tal propósito, a atuação dos xamãs é fundamental, uma vez que apenas estes sujeitos possuem os ñengáry, orações que lhes são concedidas diretamente pelas divindades e que não podem ser transmitidas a outras pessoas. Na comunicação com os Nande Ryke'y, os xamãs (denominados ñanderu $)^{11}$ recebem constantemente o tekorã, isto é, o modo de ser que deverá vigorar em cada contexto histórico. Assim, contribuem para a construção e a transformação constantes da moral indígena e do corpus de conhecimentos considerados importantes para o bem-estar social e familiar. Por outro lado, os que não são xamãs podem se beneficiar de outros tipos de orações, definidas como tihã, orações estas que podem ser ensinadas e destinadas a obter resultados nas atividades de caça, nos namoros, na defesa contra espíritos malignos etc. Ambos os tipos de orações (tihã e ñengáry) são conhecidas como ñembo'e. Entre aquelas que podem ser ensinadas, existem também as destinadas a dialogar com os chiru — como se verá adiante. 
O Áry Ypyrã (espaço-tempo atual) não é uma fase definitiva nem suficientemente estável na dinâmica do cosmo, de modo que a "procura pelo bom viver" (tekove porã) é uma busca que implica uma interpretação constante e apropriada do contexto histórico que se está vivendo. Nesses termos, há ainda uma outra fase para os índios, já iniciada e denominada Ararapire ("o fim do espaço-tempo do bom viver"). De modo análogo ao que ocorreu com a superfície da Terra no tempo das origens, também a atual será inexoravelmente destruída e purificada. Porém, desta feita, unicamente os seres puros e imortais poderão aí residir, restaurando-se as condições primordiais de equidade e simetria. Nesta perspectiva cosmológica, com suas ações, os Kaiowa podem contribuir seja para acelerar esse processo de destruição, seja, ao contrário, para tentar diminuir, tanto quanto possível, o seu ritmo, buscando-se persuadir as divindades. Nestes termos, cuidar do cotidiano é tarefa moralmente significativa, entre as quais está também a necessidade de se fazer bom uso dos instrumentos rituais - através dos quais se podem obter significativos resultados nas tentativas de se melhorar as próprias condições de vida. Dentre estes instrumentos, os chiru são indubitavelmente os mais significativos e possuem características peculiares, cuja descrição será feita a seguir.

\section{Características dos chiru}

Os Kaiowa entendem que os chiru são "objetos" muito poderosos, cuja manipulação requer certo cuidado. Neste sentido, nem todos podem lidar com eles e tampouco podem ser construídos por pessoas desprovidas de conhecimentos específicos. Em relação à sua procedência, o xamã Atanásio Teixeira afirma que Ñande Ru teria construído muitos desses objetos, tanto em forma de cruz (chiru kurusu) quanto de varas (chiru yvyra'i). Antes de subir para o yváy onde hoje reside, Nande Ru distribuiu uma parte para os Nande Rykey (divindades), enquanto outra foi deixada em seu local de subida (denominado Neypyru, hoje conhecido como "Colonia Indígena $\mathrm{n}^{\circ} 1^{1}$ ", situada no Paraguai); a intenção era que fossem posteriormente distribuídos aos kaiowa ypy ("kaiowa das origens"). Por fim, uma terceira parte foi levada consigo para sua nova morada. Para tomar posse desses chiru, os kaiowa ypy deveriam dançar e orar por pelo menos 30 dias, sendo que cada ñanderu (xamã) e/ou tamõi (avô, líder de família extensa) podia receber apenas uma unidade. ${ }^{12}$

Esta ocasião teria sido a primeira em que foram construídos e distribuídos esses instrumentos sagrados. Levando-se em conta que esses índios foram destinados pelas divindades a cuidar da Terra (Yvy), a doação desses instrumentos representa um grande auxílio para o desempenho de tal in- 
cumbência. Porém, o poder dos chiru não se transformaria automaticamente em fonte do bem, podendo, caso mal utilizados ou descuidados, representar o oposto: uma progressiva e crescente manifestação de males, chegando-se, como extrema consequência, à destruição da Terra — significando o fracasso do povo Kaiowa para com suas obrigações cósmicas.

Após este feito instaurador, os Kaiowa puderam construir outros exemplares de chiru, apenas o estritamente necessário e respeitando-se rigorosamente as regras introduzidas por Nande Ru nos tempos das origens - isto é, através de orações (ñembo'e) e de "orações que fazem o 'esfriamento' (omboroy) da madeira coletada, o que permite o controle do poder do chiru recém-"surgido" (ojehu).

Deste modo, há muitos destes "objetos" extremamente antigos e em perfeito estado de conservação, que ainda permanecem em posse dos Kaiowa e que são atribuídos à obra de Ñande Ru; outros têm sua produção atribuída a poderosos xamãs do passado. Existem ainda os que são construídos no presente, diretamente por (ou sob orientação de) esses líderes religiosos. Nos dois primeiros casos, é difícil discernir entre uns e outros no acervo, assim como estabelecer uma linha de fronteira entre esses xamãs como personagens históricos ou figuras meta-históricas. O importante aqui é registrar que, para os Kaiowa, todos os chiru são resultado de processos ocorridos no interior de uma ordem cósmica, que visam transformar um determinado objeto (o yvyra marangatu) em um objeto-sujeito (o próprio chiru), mudando o estado inicial — através do evento de "surgimento" (ojehu) de seu poder — mas não a substância. A mudança, além de estabelecer uma relação de ordem diferente entre os seres humanos ea tal substância, implica, no decorrer do processo (corte da madeira, refinamento do "objeto" e sua colocação no altar, também denominado yvyra marangatu), a produção de um "estado quente" (teko aku). Tal estado é entendido como muito delicado, associado a uma condição de desordem, que permite a afirmação de vários tipos de males, colocando-se em risco a própria organização da parte do universo onde vivem os Kaiowa. Um importante fator, então, a ser considerado é o papel desempenhado pelo operador dessa transformação, que agirá contrabalançando essa condição negativa, "esfriando" o "objeto" produzido. Tal esfriamento deve ser entendido como um processo e não como uma ação instantânea. Efetivamente, antes mesmo de se iniciar a atividade técnica de corte e elaboração do chiru, há que se proceder ao esfriamento das ferramentas utilizadas, das mãos do operador do corte, bem como das próprias árvores.

Todo este procedimento se repete em relação à construção do apyka (suporte) do altar onde será apoiado o instrumento produzido. Neste caso, o material também tem de ser específico, podendo ser de cedro ou, em sua ausência, bambu. 
$\mathrm{O}$ ato de esfriar, fazendo-se uso do conhecimento de técnicas verbais adequadas, representa, assim, uma ação que visa a reequilibrar uma situação cuja alteração foi produzida pelo próprio operador; isto é, a uma ação se contrapõe uma contra-ação, procurando-se, assim, reequilibrar e, portanto, conservar a ordem constituída. Contudo, uma vez produzidos e guardados os chiru, não se pode afirmar que o equilíbrio cósmico tenha se restabelecido. Inaugura-se, de fato, uma delicada relação entre o responsável pela conservação desses "objetos" e os próprios chiru, que passam a exigir um diálogo quase cotidiano. O diálogo, realizado através de rezas, passa a ser feito também com os "espíritos donos" das árvores sagradas de onde provêm, os quais anteriormente cuidavam desses fragmentos ora sob a custódia dos homens. Estes "donos" têm suas moradas em diferentes patamares do cosmo e exigem dos humanos o máximo cuidado para com os chiru. Nas narrativas indígenas, suas vontades e exigências muitas vezes confundem-se com as dos próprios chiru, que apresentam características psicológicas similares às dos seres humanos - como sofrer de solidão, sentir raiva etc. Com efeito, a fim de se evitar problemas, a interrupção do diálogo não pode atingir períodos superiores a quatro ou cinco dias, sob pena de os chiru se exaltarem, voltando ao estado "quente". Conforme o tempo de abandono do diálogo, os chiru podem matar animais domésticos, atrair pragas para as roças, favorecer as atividades dos espíritos malignos que vagam pela terra (ma'etirõ), produzindo enfermidades nas pessoas ou mesmo sua morte etc. A negatividade aumenta quando os chiru são abandonados, guardados de modo inadequado ou tocando o chão isto é, fora do "assento" (apyka) específico construído no altar — ou, pior ainda, quando queimados. Nestes casos, gera-se um estado generalizado (e não ocasional) de males na Terra, podendo-se chegar, em última instância, ao fim da vida neste patamar do cosmo, provocada por eventos catastróficos, enviados pelas divindades descontentes com a ação dos Kaiowa.

Tratando agora dos aspectos positivos, os chiru, como dito, foram destinados aos Kaiowa para reforçar sua ação na Terra, no desenvolvimento de suas atividades práticas e rituais. Neste sentido, os xamãs deles se servem para melhor estabelecer diálogos com as divindades distantes, nos vários patamares do cosmo. Os encarregados de sua guarda os mantêm em suas mãos durante o acompanhamento dos rituais religiosos. Além disso, os chiru servem como remédio para todos os tipos de doença, utilizando-se a água onde foram imersos para ingerir ou lavar partes doentes do corpo.

Já foi afirmado que, uma vez construídos, os chiru mudam de estado mas não de substância. De fato, dependendo do solo de origem da árvore de onde foi extraída a madeira, esse "objeto" adquirirá uma característica específica. Teremos, assim, entre outros: Chiru itakui — sua origem é um 
solo de pedras fragmentadas; Chiru itavera — originário de um local onde há pedras brilhantes; Chiru itahu — provém de pedras escuras; e Chiru pirary — sua árvore de origem cresceu nas águas.

Dependendo dessas características originárias, são necessários cantos específicos para cuidar dos chiru, que devem ser entoados ou por aqueles que deles estão cuidando, ou por aqueles que deles se servem. Os cantos podem ser realizados na presença dos chiru ou à distância, através de ñengáry — orações que visam a comunicação à distância, utilizadas nas viagens xamânicas. A comunicação com os chiru leva em conta essas diferenças, uma vez que também apresentam e assumem comportamentos diferentes; os itakui, por exemplo, são os mais bravos e exigem maior cuidado, enquanto outros necessitam de cantos mais longos - caso dos itahu.

\section{As reservas de Dourados e Sassoró e a trajetória dos chiru}

Retornando especificamente à trajetória dos chiru, relato a seguir as vicissitudes da maior parte destes "objetos" em duas reservas habitadas por Kaiowa: Dourados e Sassoró.

A reserva de Dourados situa-se no município homônimo e foi instituída em 1917, com uma superfície de 3.474 ha. O local encontra-se no interior da bacia do rio Brilhante, um território kaiowa. Em 1923, um ex-funcionário do SPI deslocou para Dourados algumas famílias terena, que rapidamente entraram em conflito com os Kaiowa locais (Mura \& Thomaz de Almeida 2003). Após essa primeira migração terena, houve outras, uma vez que o SPI considerou vantajoso trazer esses indígenas para "ensinar" os Kaiowa a cultivarem mais eficazmente a terra, visto que os primeiros se apresentavam como "mais civilizados". No final de 1950, Cardoso de Oliveira (1976:86-87) relatou a existência, em Dourados, de quatro comunidades, três delas lideradas por kaiowa e uma por terena, sendo os espaços ocupados pelos primeiros então preponderantes, cada grupo mantendo certa autonomia. A família mais influente e numerosa da área era a dos Fernandes, seguida por aquela dos Isnard, ambas kaiowa.

Nos anos 1970, o equilíbrio interno de Dourados mudou, devido à perda de espaço territorial por parte da família Fernandes, com o avanço dos Terena, sob a liderança de Ramão Machado. Com a divisão formal da reserva em duas aldeias, Jaguapiru e Bororó, Ramão passou a ser "capitão" da primeira, deixando a segunda sob a orientação do influente kaiowa Ireno Isnard.

O surgimento de Ramão como liderança deveu-se principalmente ao apoio obtido da Igreja Metodista (que lhe entregou um trator), da Missão Evangélica Caiuá e do então chefe de posto, todos considerando que tal 
apoio contribuiria para o "desenvolvimento" da reserva. Na época, em plena sintonia com as atividades regionais, a própria FUNAI contribuiu para desmatá-la, abrindo espaço para a mecanização da agricultura. A partir daquele momento, segundo informam os Kaiowa, o líder terena, com a ajuda de sua "polícia indígena", teria praticado inúmeras violências e expulsões de líderes políticos e religiosos, chegando a ter, com a morte de Ireno Isnard (ocorrida no fim dos anos 1980), o pleno controle da reserva.

O sucessor de Ireno, Carlito Oliveira, assumiu o poder por poucos anos. Durante esse período, juntou muitos chiru, entre os quais vários que estavam em poder do falecido líder. No começo dos anos 1990, no pátio de Carlito, foi construída uma oygusu — as construções antigamente utilizadas pelos Kaiowa como residência, hoje também denominadas ogapysy (de oga ypy sy, "casa mãe das origens"), destinadas ao uso ritual e como símbolo de diferenciação étnica. Apesar de não obrigatório, os índios indicam essas construções como o lugar mais apropriado para se conservar os chiru.

No final dessa década, algumas famílias kaiowa passaram a denunciar às autoridades externas (Ministério Público Federal e Polícia Federal) as violências sofridas. Algumas lideranças, fazendo uso político da tradição religiosa kaiowa, passaram a se definir, especialmente perante os brancos, como "caciques", termo utilizado entre os Guarani de Mato Grosso do Sul como sinônimo de "rezador". Embora não sejam considerados indivíduos que tenham alcançado o status de ñanderu (xamã), estes podem ser yvyra'ija (ajudantes/aprendizes), apoiando-se na figura dos mestres ou num conjunto destes, que oficiam as principais cerimônias desenvolvidas na reserva. Hoje, em Dourados, não existem xamãs, que precisam então ser periodicamente convidados de fora. Em sua ausência, os "caciques" passaram a reivindicar a tradição. Entre estes encontra-se Adimiro Arce, atualmente em posse de uma ogapysy, onde conserva a maioria (20) dos chiru da reserva, incluindo os que Carlito havia reunido. Com o consenso dos mais importantes ñanderu da região, Adimiro cuida desses importantes "objetos", que são periodicamente visitados e utilizados pelos xamãs durante os rituais organizados pelo "cacique".

Passaremos agora à reserva de Sassoró, localizada no município de Tacuru e compreendida na bacia do rio Iguatemi. Sua criação data de 1928, com uma superfície de 1.932 ha, nas proximidades do porto homônimo, no rio Hovy, porto este utilizado pela Cia. Matte Larangeira para transporte da erva coletada na região. Sassoró encontra-se no interior de um território (tekoha guasu) outrora densa e homogeneamente ocupado pelos Kaiowa, tendo cada comunidade política seu lugar de origem (tekoha) em diversos locais desse amplo espaço. Nos anos 1940 e 1950, essa região foi atingida por epidemias (malária, sarampo, catapora e tuberculose) (Brand 1997), 
provocando intensos conflitos entre famílias rivais, que atribuíam, umas às outras, práticas de feitiçaria, indicadas como causa principal dessas doenças. Até o fim dos anos 1960, porém, a maior parte da população desse território residia fora da reserva; as famílias mantendo relações com aquelas residentes no espaço delimitado pelo Estado. Foi entre este período e a primeira metade dos anos 70 que, atraído pela Missão Evangélica Caiuá (MEC) que prestava atendimento médico - e/ou expulso pelos fazendeiros, um significativo contingente de famílias passou a residir em Sassoró.

Em meados dos anos 1960, a MEC havia construído uma sede adjacente à reserva. Fornecendo, além de assistência médica, roupas e outras utilidades, conseguiu aproximar boa parte das famílias do local a essa sede, chegando a ser formada uma estrutura de vila, organização espacial totalmente alheia aos Kaiowa. As demais famílias, rivais das primeiras, permaneciam nos "fundos" da reserva, longe das práticas missionárias e do chefe do posto que, durante os anos 1970, apoiava a política da Missão.

Segundo relatos dos índios, a violência perpetrada pelo pastor Benedito Troquez chegava a atos extremamente ofensivos para os Kaiowa. Emblemático é o caso do ñanderu Quincas que, no final dos anos 1970, procedendo do tekoha de Mbarakay, teve seu mbaraka (chocalho), isto é, um instrumento ritual, queimado em público por esse pastor, que acusou o xamã de praticar obra do diabo (cf. Thomaz de Almeida 1991). Após esta ação, Quincas voltou a trabalhar nas fazendas das vizinhanças do seu tekoha de origem, retornando a Sassoró somente em meados dos anos 1980.

Neste clima de terror instaurado na reserva, as famílias dos "fundos" somente podiam praticar suas rezas de modo clandestino, e era justamente na clandestinidade e num clima de medo que ocorria a transmissão dos chiru, com nefastas implicações para boa parte dos Kaiowa.

Hoje em dia, a residência de Juarez Borvão abriga 17 chiru, em perfeito estado de conservação e bem cuidados. Mas nem sempre foi assim, uma vez que Juarez só passou a ter obrigação de cuidar desses "objetos" a partir de 1987, quando lhe foram entregues. Antes, por mais de uma década, o destino desses chiru foi marcado pelo abandono e pela total falta de cuidados. Vejamos suas trajetórias.

Os 17 chiru foram reunidos nas mãos de Estanislau até meados dos anos 1970. Estes procediam de vários líderes religiosos e de famílias extensas, de distintos lugares no interior do tekoha guasu onde se encontra Sassoró. Uma parte era de Mbopi, importante xamã do tekoha de Pueblito Kue, que faleceu nos anos 1960; outros eram de Galino, relevante xamã do passado, de Sassoró; havia ainda os chiru de Antonino, neto de Galino e também ñanderu, alguns outros de Catulino e um de Cassimiro, xamã do tekoha de 
Samakuã. A concentração ocorreu através dos parentes destas importantes figuras que, impossibilitados de cuidar dos "objetos" sagrados, entregaramnos a Estanislau, que assumiu o compromisso. Contudo, Estanislau desatendeu a esse pedido quando, pressionado pelo pastor da MEC, "converteu-se" formalmente ao cristianismo, abandonando os chiru recebidos, relegando-os a um canto, no chão de sua residência.

O abandono dos chiru foi interpretado por várias famílias kaiowa como a causa de muitas doenças e da instauração de um clima de hostilidade e violência dentro da reserva, elementos tidos como contrários ao correto modo de ser e viver (teko porã). O próprio Estanislau passou a sofrer de alucinações, ouvindo continuamente vozes, tanto na vigília quanto no sono, doença esta interpretada pelos Kaiowa como efeito dos males trazidos pelos chiru, já há muito em estado quente.

A mudança política na reserva, ocorrida em meados dos anos 1980, criou novas condições para que os Kaiowa pudessem oficiar à "luz do sol" suas cerimônias religiosas; o novo "capitão" passando a apoiá-las, e o novo chefe de posto não opondo obstáculos. A Missão também mudou de postura, sendo sua prática menos opressiva. Assim, em 1987, foi organizado um jeroky guasu (grande dança ritual) em Sassoró, com a presença de importantes xamãs, procedentes de várias regiões. O encontro foi possível por meio do apoio do PKÑ (sobre o qual se falou no início deste artigo), que forneceu alimentos e garantiu o transporte dos convidados.

Em um diálogo à distância com os chiru abandonados (através de ñengáry, orações específicas), foi possível estabelecer quem seria o novo escolhido para deles cuidar, os próprios chiru indicando Juarez. Foi assim que esses importantes "objetos" foram primeiramente esfriados (oñemboroy), sendo então transportados e entregues ao novo responsável. Até aquele momento, Juarez não tinha os conhecimentos apropriados para desempenhar a função de guardião, mas ao ser indicado, os próprios xamãs lhe repassaram conhecimentos básicos, permanecendo incumbidos de visitá-lo periodicamente, por meio de viagens físicas ou ñengáry.

A partir desse jeroky guasu ficou estabelecido que tal evento seria repetido aproximadamente a cada quatro anos, periodicidade que foi mantida até 1998, quando o encontro foi realizado contemporânea e complementarmente à aty guasu intercomunitária, em Sassoró. Após essa data, jeroky guasu não foram mais realizados nesta reserva, tornando-se raros também em outras localidades. Com efeito, mudanças na configuração do quadro de aliados dos índios (o PKÑ saiu de cena) e uma diversificação de interesses faccionais na disputa para se organizar e implementar as aty guasu e jeroky guasu levaram a uma certa estagnação, a qual, a partir de 2006, vem sendo superada atra- 
vés da ideação e implementação — pelos próprios Guarani — de ñanderu ñomono'o, isto é, encontros de sabedoria xamanística. Sob esta nova forma e denominação, os xamãs pretendem continuar discutindo as especificidades do tekorã (o modo de ser periodicamente enviado pelos deuses); os chiru permanecendo como elementos fundamentais nestes eventos.

\section{Chiru e tradição de conhecimento}

Em um livro organizado por Fredrik Barth, sobre a relação entre escala e organização social, Theodore Schwartz (1978) propõe considerar a cultura não como algo abstrato ou sistêmico, mas pelas implicações de sua distribuição diferenciada entre os indivíduos que compõem um determinado grupo social. Criticando a clássica oposição durkheimiana entre "sociedades simples" (calcadas em uma solidariedade mecânica) e aquelas "complexas" (baseadas na solidariedade orgânica), este autor coloca em evidência que até mesmo em pequenas comunidades fundadas nas relações de parentesco e na vida doméstica existem papéis individuais diversificados, que tornam as interações muito mais complexas do que comumente lhes é atribuído. Isto denotaria uma distribuição de saberes e formas de experiências diversificadas, sendo que a organização social das diferenças culturais se tornaria importante para compreender o processo de formação comunitária. Na conclusão deste livro, o próprio Barth toma como ponto de referência analítica a visão proposta por Schwartz, buscando justamente mecanismos para descrever (em distintos níveis de escala social e territorial) como saberes, valores, ideias etc. são distribuídos e organizados. Procura-se, desta forma, realizar um mapeamento dos elementos culturais em um determinado meio social e, mais ainda, verificar como estes elementos estão sendo continuamente canalizados, a partir de fluxos culturais mais abrangentes.

A procura por lógicas de organização social da cultura levou Barth a se concentrar sobre a formação e propagação de tradições e sub-tradições de conhecimento (Barth 1987, 1993, 2000a e 2000b). O estudo das tradições e sub-tradições de conhecimento proposto pelo autor atenta para uma dimensão empírica das mesmas em suas construções, resultantes de interações entre atores social e politicamente diferenciados. Explicita-se, assim, uma estrutura específica de ação social, baseada na relação entre os atos dos indivíduos, os eventos por estes gerados e as experiências que, das interpretações desses atos e eventos, são engendradas pelos próprios agentes (Barth 2000b). A experiência, sendo algo cumulativo, permite a formação e o armazenamento, nos atores, de "estoques culturais" (Barth 1993:173), entendidos como em contínua modificação. Nestes 
termos, uma cosmologia seria uma construção sempre inacabada (Barth 1987), expressa por meio da contribuição de vários pontos de vista, frutos de experiências diversificadas e a partir de contextos históricos determinados. Ocorre, porém, que estes pontos de vista não são equivalentes entre si, sendo hierarquizados, alguns expoentes gozando de maior autoridade e legitimidade que outros no fomento e na interpretação de valores e ideias, bem como do quadro moral e normativo. Assim, a própria visão cosmológica será moldada a partir de uma configuração específica de papéis sociais, que impulsionam as tradições de conhecimento às quais aferem os atores que revestem justamente esses papéis.

Em outro artigo (2000b), Barth procura, em uma perspectiva comparativa, remarcar justamente as diferenças entre dois tipos de tradições de conhecimento (as do sudeste da Ásia e as da Melanésia). O autor centra sua atenção sobre as modalidades de organizar, valorizar e transmitir o conhecimento pelos gurus, por um lado e, por outro, pelos iniciadores. O seu escopo declarado é "trazer à tona as fontes de duas economias informacionais basicamente distintas, através da identificação das pressões que direcionam os esforços intelectuais daqueles que assumem dois papéis muito diferentes" (Barth 2000b:146). Em Bali, para garantir a manutenção ou a ascensão de status, os gurus precisam adquirir conhecimentos ininterruptamente. Para tal propósito, além de incorporarem saberes por meio da leitura, estes oficiantes viajam, buscando adquirir conhecimentos inéditos. Em Nova Guiné, por seu turno, os iniciadores transacionam conhecimentos com os ancestrais, iniciando os neófitos através de performances que objetivam criar uma atmosfera de mistério e segredo, através da manipulação dos já referidos "símbolos concretos" (Barth 1987). Em relação aos conhecimentos que os oficiantes possuem, estes são transacionados com os ancestrais, não sendo transmitidos aos iniciandos.

Cotejando as duas economias informacionais, Barth considera que o status do guru se dá através da transação "para baixo" de conhecimentos verbalizados, armazenáveis através da escrita em suportes externos à memória dos indivíduos. Em relação ao iniciador melanésio, afirma que o status é obtido em certa medida de modo contrário ao do guru, negando-se a comunicação verbal para baixo dos saberes possuídos, o status lhe sendo atribuído pela eficácia de sua performance, que demonstraria a posse dos conhecimentos transmitidos pelos ancestrais - transação "para cima". Desta forma, pode-se arguir, afirma o autor, que a tradição centrada na figura do guru é rica em massa de informações, sendo os conhecimentos fortemente descontextualizados e facilmente transportáveis por um número significativo de oficiantes e neófitos, o que permite uma significativa propagação dos mesmos no tempo e no espaço. Contrariamente, a forma de conhecimento centrada na figura do iniciador, "ainda que possa ser forte no que diz respeito 
a 'significado', é fraca quanto à abstração e transportabilidade, bem como relativamente limitada em termos de massa" (Barth 2000b:160).

O argumento de Barth permite constatar que no caso dos xamãs kaiowa ocorre algo análogo ao descrito para os iniciadores melanésios. De fato, embora entre esses índios a palavra seja sumamente valorizada (Melià et alii 1976; Chamorro 1995 e 1998; Montardo 2009), esta é relevante mais por sua musicalidade, poeticidade e eficácia mágico-religiosa, do que pelo conteúdo transmitido pela linguagem. Não nos referimos aqui à circulação de ideias, conceitos, imagens e técnicas - cujo fluxo é em certa medida livre entre os índios, permitindo a transação "horizontal" desses elementos culturais - mas a certas formas de se organizar, hierarquizar e atribuir valor a estes fatores, construindo-se uma ordem moral e produzindo-se meios através dos quais os indígenas possam agir e ser protagonistas na dinâmica do cosmo. Nestes termos, as palavras que procedem dos deuses são privilegiadas e adquiridas apenas por oficiantes que possuem ñengáry - ou seja, rezas que servem como meio de locomoção e de comunicação com as divindades. Os conhecimentos mais importantes, através dos quais se forma o quadro moral e normativo, são transacionados "para cima", exclusivamente por operadores autorizados, como os xamãs. Ocorre, contudo, que para que o xamã possa chegar a realizar esse tipo de transação, ele precisa formar-se como tal, sendo instruído por outro xamã, que na maioria dos casos pertence à sua própria rede familiar. Durante esta fase de formação, lhe é proibido comunicar em público as informações recebidas (do instrutor ou das divindades), sob pena de serem "cortadas as asas" do iniciando - como afirma o conceituado xamã Atanásio - fracassando totalmente em seu intento e perdendo legitimidade. Esse conteúdo pode ser socializado apenas com poucos íntimos, no âmbito de seu espaço doméstico.

Nessa fase de formação, bem como na atuação já enquanto xamã, os chiru revestem-se de grande importância. Estes substituem os objetos, menos poderosos, de yvyra paje, com os quais o neófito costuma começar seu aprendizado. A escolha de sua dimensão, forma, poder e peculiaridade, conforme descrito anteriormente, dependerá do nível de maturação (aguyje) alcançado pelo neófito, bem como do repertório de objetos disponíveis e/ou do alcance da família em que o futuro xamã está inscrito.

Como foi possível observar, ao longo da história do cosmo, os chiru foram distribuídos e construídos de modo tal que cada família possuísse pelo menos algumas unidades, podendo seus cuidados e transmissão garantir um acervo difuso destes importantes objetos/sujeitos, de modo que um aprendiz xamã possa ter acesso a eles, de qualquer lugar. Porém, como descrevi ao longo deste trabalho, especialmente nas décadas de 1960 e 1970, a dominação colonial exercida sobre os Kaiowa teve como consequência a perseguição 
das práticas xamanísticas, sendo os instrumentos rituais abandonados ou descuidados por indígenas, ou mesmo queimados por agentes missionários. Este processo acarretou um desequilíbrio distributivo dos chiru, interpretado pelos índios como algo que afeta a saúde do cosmo.

A necessidade de resgatar muitos destes objetos das péssimas condições em que se encontravam no final da década de 1970 representou uma importante contribuição para a determinação de formas inéditas de organização e circulação de saberes entre os Kaiowa, bem como de manifestações rituais. As aty guasu, os jeroky guasu e, mais recentemente, os ñanderu ñomono'o são claras tentativas indígenas neste sentido, representando instâncias de interação social, política e religiosa supralocais.

Seguramente este nível de interação permite a produção e a acumulação paulatina de experiências que contribuem para modificar e melhor adaptar a vida social e religiosa dos Kaiowa às circunstâncias históricas do momento. Permite também a determinação de processos singulares, que nos possibilitam uma melhor compreensão do papel que os chiru desempenham nesse processo de adaptação sociocósmica.

A descrição da trajetória dos chiru nas reservas de Dourados e Sassoró permitiu demonstrar um processo de concentração desses símbolos concretos, no qual os Kaiowa instituem (embora ainda não formalmente) o papel de "guardião, o que gera obrigações para com os "objetos" custodiados e com os ñanderu, que lhes repassam as normas de conduta a serem adotadas frente aos chiru, formando-se deste modo um vínculo privilegiado entre guardiães e xamãs. Esse tipo de relação pode levar à formação de novos ajudantes (yvyra'ija) que, dependendo da própria dedicação, também poderão tornar-se xamãs. Deste modo, inauguram-se mecanismos diferentes de se interagir com os chiru, instituindo-se uma dimensão coletiva específica, que vem a se somar e articular com formas mais domésticas de se lidar com esses objetos/sujeitos. Estes mecanismos, ademais, permitem suprir parcialmente os vazios provocados ao longo do tempo pelos efeitos da dominação colonial, permitindo que indivíduos de famílias hoje não mais em posse de chiru possam vir a se relacionar com estes, adquirindo conhecimento sobre as regras necessárias para que tal relação seja considerada adequada, segundo as exigências cosmológicas kaiowa.

Concluindo, pode-se afirmar que as vicissitudes dos chiru e as respostas dadas pelos indígenas representam elementos importantes na continuada construção da tradição de conhecimento promovida pelos Kaiowa. Estes indígenas fazem com que as fragilidades deste tipo de tradição frente à realidade contemporânea sejam em certa medida amenizadas, através da elaboração de formas complementares de organização, valorização e transmissão de saberes, tornando mais complexos os mecanismos de sua reprodução. 
Recebido em 23 de março de 2010

Aprovado em 20 de maio de 2010

Fabio Mura é antropólogo, professor da Universidade Federal da Paraíba (UFPB).

E-mail: <fabiomura64@gmail.com>

\section{Notas}

* No tocante às regras de acentuação das palavras em guarani, seguirei a nomenclatura mais utilizada no Paraguai, não grafando o acento agudo nas palavras oxítonas, que constituem a maioria na língua indígena. A ocorrência da apóstrofe indica parada glotal. Por motivos técnicos do editor de textos do computador, utilizarei dois símbolos distintos para indicar a nasalização: nas vogais "a" e "o", será utilizado o til; já para "i", "e" e "u", utilizarei o acento circunflexo. O "y" é a sexta vogal guarani, de som gutural; no caso específico da palavra "te'yi", esta letra, além de gutural, é também nasalizada.

${ }^{1}$ Agradeço a Alexandra Barbosa da Silva e a Guillermo Wilde pelas preciosas observações feitas na leitura de versões preliminares deste trabalho, que em muito contribuíram para minhas reflexões.

${ }^{2} \mathrm{O}$ termo Kaiowa é uma corruptela da palavra guarani "Ka'aguygua" (habitantes do mato), termo genérico com o qual até o século XIX eram denominadas as populações situadas no cone sul do atual estado de Mato Grosso do Sul e no leste do Paraguai. A autodenominação deste povo indígena é Paî-Tavyterã, como são conhecidos atualmente no lado paraguaio da fronteira. O termo é a composição de "Paî (homem) - táva (morada) - yvy (terra) - ete (verdadeiro) - rã (sufixo de futuro)". Isto é, os "homens que serão destinados a viver (com relação ao tempo-espaço das origens) na verdadeira morada da terra". Contudo, há que se levar em conta que, no Brasil, o termo "Kaiowa" é hoje comumente aceito e o mais utilizado pelos indivíduos deste povo, razão pela qual a eles me referirei com esta denominação.

${ }^{3}$ Como "reservas", refiro-me às terras indígenas instituídas pelo Serviço de Proteção aos Índios, nas primeiras décadas do século XX.

${ }^{4}$ Árvore leguminosa de variedades diversas, conhecida no Brasil também com o nome de "pau de bálsamo".

${ }^{5} \mathrm{Na}$ literatura específica sobre esses indígenas, existe, de fato, total ausência de descrição e análise destes importantíssimos objetos/sujeitos. Por tal razão, o presente 
artigo baseia-se fundamentalmente em dados de campo por mim coletados entre fevereiro de 2001 e junho de 2005, período durante o qual realizei minha pesquisa entre os Kaiowa, destinada à formulação da tese de doutorado (Mura 2006).

${ }^{6}$ O Mato Grosso do Sul concentra hoje a maior parte da população guarani do Brasil, dividida entre os Kaiowa e os Ñandéva. Segundo dados do sistema de informação da FUNASA (SIASI), os Kaiowa e os Nandéva do sul deste estado somavam, em 2005, aproximadamente 40.000 indivíduos. Com os Kaiowa constituindo cerca de três quartos desse total, pode-se dizer que estamos considerando um universo populacional de aproximadamente 30.000 pessoas no lado brasileiro da fronteira. Com relação à situação populacional no Paraguai, o "II Censo Nacional Indígena de Población y Viviendas 2002" (DGEEC 2003) aponta pouco mais de 13.000 indivíduos Paî-Tavyterã.

${ }^{7}$ Brasil, Argentina e Uruguai contra o Paraguai.

${ }^{8}$ Os xamãs Inácio Sousa e Hermenegildo Medina, respectivamente da reserva de Porto Lindo e do acampamento indígena de Potrero Guasu, fizeram justamente este tipo de comparação, marcando a diferença entre eles e os Kaiowa, que possuem chiru.

${ }^{9}$ Ao analisar os rituais de iniciação entre os habitantes das terras altas da Nova Guiné, Barth (1987) define como "símbolos concretos" elementos como sangue, taro, ossos, caveiras etc., que permitem a realização de performances com um conteúdo informacional analógico, baseado na própria natureza desses objetos, os quais possuem propriedades específicas (indicando fertilidade, força, pureza, impureza etc.). Os chiru também possuem características distintivas e são veículos de informações e poderes bem definidos.

${ }^{10}$ Apresento aqui, de modo sintético e esquemático, alguns aspectos da arquitetura e da dinâmica do cosmo entre os Kaiowa, baseando-me principalmente nos dados apresentados na terceira parte de minha tese de doutorado (Mura 2006), à qual remeto para aprofundamentos, juntamente com os importantes trabalhos de Cadogan 1962; Melià et alii 1976; Chamorro 1995 e 1998, e Pereira 2004.

${ }^{11}$ Em letra minúscula, para não ser confundido com "Ñande $\mathrm{Ru}$ ", uma das divindades mais importantes, como já visto.

${ }^{12} \mathrm{O}$ xamã Luiz, neto do também xamã José Borbon - que foi um dos principais informantes de Schaden (1974) - narra outra versão: no tempo das origens (áry ypy), Pa'i Tani, uma divindade teria com um raio rachado uma árvore sagrada (o yvyra marangatu), produzindo-se mais de 500 pedaços, dois ou três deles sendo distribuídos para cada tamõi (chefe da família extensa). 


\section{Referências bibliográficas}

BARTH, Fredrik. 1978. "Conclusions". In: F. Barth (ed.), Scale and social organization. Oslo: Universitetsforlaget. pp. 253-273

1987. Cosmologies in the making. A generative approach to cultural variation in inner New Guinea. Cambridge: Cambridge University Press. 1993. Balinese worlds. Chicago: The University of Chicago Press. . 2000a. "O guru e o iniciador: transações de conhecimento e moldagem da cultura no sudeste da Ásia e na Melanésia". In: T. Lask (org.), O guru, o iniciador e outras variações antropológicas. Rio de Janeiro: Contra Capa Livraria. pp. 141-166 . 2000b. "Por um maior naturalismo na conceptualização das sociedades". In: T. Lask (org.), O guru, o iniciador e outras variações antropológicas. Rio de Janeiro: Contra Capa Livraria. pp. 167-186.

BRAND, Antonio J. 1997. O impacto da perda da terra sobre a tradição kaiowá/guarani: os difíceis caminhos da palavra. Tese de doutorado, PUC/RS. . 2001. "Os Kaiowa/Guarani no Mato Grosso do Sul e o processo de confinamento - a entrada de 'nossos contrários'". In: CIMI, Comissão Pró-Índio, MPF (org.), Conflitos de direitos sobre as terras guarani kaiowá no estado de Mato Grosso do Sul. São Paulo: Palas Athena. pp. 93-131.

CADOGAN, León. 1962. "Aporte a la etnografía de los guaraní del Amambay, alto ypané". Revista de Antropologia, $\mathrm{X}(1-2): 43-91$.

CARDOSO DE OLIVEIRA, Roberto. 1976. Do índio ao bugre: o processo de assimilação dos Terêna. Rio de Janeiro: Livraria Francisco Alves Editora.
CHAMORRO, Graciela. 1995. Kurusu Ne'ëngatu. Palabras que la historia no podría olvidar. Assunção: Centro de Estudios Antropológicos. . 1998. A espiritualidade guarani: Uma teologia ameríndia da palavra. São Leopoldo: Sinodal.

CORRÊA FILHO, Virgílio. 1969. História de Mato Grosso. Rio de Janeiro: Instituto Nacional do Livro/ Ministério da Educação e Cultura.

DGEEC. 2003. II Censo nacional indígena de población y viviendas 2002. Pueblos indígenas del Paraguay. Resultados finales. Paraguay: DGEEC Publicaciones.

ELLIOT, João Henrique. 1848. “Itinerário das viagens exploradoras emprehendidas pelo Sr. Barão de Antonina para descobrir uma via de communicação entre o porto da villa de Antonina e o Baixo-Paraguay, na Província de Mato Grosso". Revista do Instituto Histórico Geográfico Brasileiro, IX:17-42.

GADELHA, Regina M.A.F. 1980. As missões jesuíticas do Itatim: um estudo das estruturas sócio-econômicas coloniais do Paraguai (séc. XVI e XVII). Rio de Janeiro: Paz e Terra.

LEHNER, Beate. 2002. "Territorialidad guarani. Ensayo sobre la relación territorio-organización sócio-política de los Ava-Guarani y Paî-Tavyterã". Servicios Profesionales Sócio-Antropológicos y Jurídicos. Paraguai. Mimeo.

LIMA, Antonio Carlos de S. 1995. Um grande cerco de paz: poder tutelar e indianidade no Brasil. Petrópolis: Vozes.

LOPES, Joaquim Francisco. 1850. "Itinerário de... encarregado de explorar a melhor via de communicação entre a Província de São Paulo e a de Matto Grosso pelo Baixo Paraguay". Revista 
do Instituto Histórico Geográfico Brasileiro, XIII:315-335.

MANUSCRITO DA COLEÇÃO DE ANGELIS (MCA). 1951. Jesuítas e bandeirantes no Guairá, I. Biblioteca Nacional, Divisão de Obras Raras e Publicações. MELIÀ, Bartomeu; GRÜNBERG, Friedl; GRÜNBERG, Georg. 1976. "Los PaîTavyterã: etnografia guarani del Paraguay contemporaneo". Revista del Ateneo Paraguayo, IX(1-2):151-295.

MONTARDO, Deise Lucy Oliveira. 2009. Através do mbaraka: música, dança e xamanismo guaraní. São Paulo: Edusp.

MURA, Fabio. 2000. Habitações kaiowá: formas, propriedades técnicas e organização social. Dissertação de mestrado, PPGAS/ Museu Nacional/UFRJ. . 2004. "O tekoha como categoria histórica: elaborações culturais e estratégias kaiowa de construção do território". Fronteiras, Revista de História, VIII(15):109-143.

.2006. À procura do "bom viver": território, tradição de conhecimento e ecologia doméstica entre os Kaiowa. Tese de doutorado, PPGAS/Museu Nacional/UFRJ.

MURA, Fabio; THOMAZ DE ALMEIDA, Rubem F. 2002. Relatório antropológico de revisão de limites da T.I. Porto Lindo (Jakarey) e identificação da terra indígena Guarani-Ñandéva do Yvy Katu. FUNAI. Mimeo.

. 2003. Levantamento situacional sobre o posto indígena Dourados. Ministério Público Federal de Dourados (MS). Mimeo.

OLIVEIRA, João Pacheco de. 1988. O nosso governo: os Ticuna e o regime tutelar. São Paulo: Marco Zero.

PEREIRA, Levi Márquez. 2004. Imagens kaiowa do sistema social e seu entorno. Tese de doutorado, Universidade de São Paulo.

PIMENTEL BARBOZA, Genésio. 1927. Relatório apresentado ao Inspetor do
SPI do estado de Matto Grosso. Rio de Janeiro: Documentação do Museu do Índio/FUNAI.

SCHADEN, Egon. 1974. Aspectos fundamentais da cultura guarani. São Paulo: E.P.U./EDUSP.

SCHWARTZ, Theodore. 1978. "The size and shape of a culture". In: F. Barth (ed.), Scale and social organization. Oslo: Universitetsforlaget. pp. 215-252.

SUSNIK, Branislava. 1979-80. "Etnohistoria de los Guaranies: epoca colonial". Los Aborígenes del Paraguay, II:205-219.

SWARTZ, Marc J.; TURNER, Victor W.; TUDEN, Arthur. 1966. "Introduction". In: M. Swartz, V. W. Turner e A. Tuden (eds.), Political anthropology. Chicago: Aldine. pp. 1-41.

THOMAZ DE ALMEIDA, Rubem F. 1991. O projeto kaiowa-ñandeva: uma experiência de etnodesenvolvimento junto aos Guarani-Kaiowa e Guarani-Ñandeva contemporâneos do Mato Grosso do Sul. Dissertação de mestrado, PPGAS/Museu Nacional/UFRJ. 2001. Do desenvolvimento comunitário à mobilização política: o Projeto Kaiowa-Ñandeva como experiência antropológica. Rio de Janeiro: Contra Capa Livraria.

TURNER, Victor W. 1974. Dramas, fields and metaphors. Symbolic action in human society. Ithaca e Londres: Cornell University Press.

WILDE, Guillermo. 2003. "Poderes del ritual e rituales del poder: un análisis de las celebraciones en los pueblos jesuíticos de Guaraníes". Revista Española de Antropología Americana, XXXIII:203-229.

. 2008. "El enigma sonoro de Trinidad: ensayo de etnomusicología histórica". Resonacias, XXIII. (Instituto de Música de la Pontificia Universidad Católica de Chile). [http://www. resonancias.cl/resonancias-no-23] ISSN: 0717-3474. 


\section{Resumo}

Os Kaiowa atribuem grande importância a certos tipos de "objetos", que exigem um cuidado especial: os chiru (cruzes e varas). No tempo das origens, cada família extensa recebeu os primeiros chiru, potencialmente podendo obter os benefícios derivados de seu poder. Estes "objetos", contudo, se descuidados, podem surtir o efeito contrário, provocando pragas e doenças. Por tal razão, muitos chiru foram cuidadosamente conservados e transmitidos por gerações, até os dias de hoje. Pretendo aqui retraçar a trajetória dos chiru, procurando reconstruir sua distribuição e redistribuição, bem como das relações e interações desenvolvidas por xamãs e aprendizes. Estes fatos são relevantes para a construção da tradição de conhecimento indígena, bem como de sua historicidade, na situação histórica contemporânea, em que os índios buscam constantemente alcançar o equilíbrio cósmico almejado.

Palavras-chave Guarani Kaiowa, Tradição de conhecimento, Objetos simbólicos, Dominação colonial
Abstract

Certain 'objects' requiring special care have a great relevance for the Kaiowa: the chiru (crosses and sticks). At the beginning of time, every extended family received their first chiru, allowing them to obtain the benefits of their power. Failing to care properly for these 'objects,' however, can generate the opposite effect, causing misfortune and diseases. Consequently many chiru have been carefully conserved and passed on from one generation to the next. Here I trace the trajectory taken by the chiru, reconstituting their paths of distribution and redistribution, as well as the relationships and interactions between shamans and their apprentices. These facts play a key role in the construction of the indigenous knowledge tradition and historicity, all of which influence the contemporary historical situation in which the Kaiowa strive to attain and maintain a desired cosmic equilibrium.

Key words Guarani-Kaiowa, Knowledge tradition, Symbolic objects, Colonial domination. 